\title{
Influence of Salts on the Adsorption of Lysozyme on a Mixed-Mode Resin
}

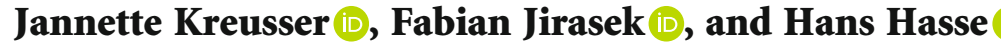 \\ Laboratory of Engineering Thermodynamics (LTD), TU Kaiserslautern, Kaiserslautern, Germany \\ Correspondence should be addressed to Fabian Jirasek; fabian.jirasek@mv.uni-kl.de
}

Received 19 November 2020; Revised 20 December 2020; Accepted 7 January 2021; Published 25 January 2021

Academic Editor: Senthil Kumar Ponnusamy

Copyright (c) 2021 Jannette Kreusser et al. This is an open access article distributed under the Creative Commons Attribution License, which permits unrestricted use, distribution, and reproduction in any medium, provided the original work is properly cited.

\begin{abstract}
Mixed-mode chromatography (MMC), which combines features of ion exchange chromatography (IEC) and hydrophobic interaction chromatography (HIC), is an interesting method for protein separation and purification. The design of MMC processes is challenging as adsorption equilibria are influenced by many parameters, including ionic strength and the presence of different salts in solution. Systematic studies on the influence of those parameters in MMC are rare. Therefore, in the present work, the influence of four salts, namely, sodium chloride, sodium sulfate, ammonium chloride, and ammonium sulfate, on the adsorption of lysozyme on the mixed-mode resin Toyopearl MX-Trp-650M at pH 7.0 and $25^{\circ} \mathrm{C}$ was studied systematically in equilibrium adsorption experiments for ionic strengths between $0 \mathrm{mM}$ and $3000 \mathrm{mM}$. For all salts, a noticeable adsorption strength was observed over the entire range of studied ionic strengths. An exponential decay of the loading of the resin with increasing ionic strength was found until approx. $1000 \mathrm{mM}$. For higher ionic strengths, the loading was found to be practically independent of the ionic strength. At constant ionic strength, the highest lysozyme loadings were observed for ammonium sulfate, the lowest for sodium chloride. A mathematical model was developed that correctly describes the influence of the ionic strength as well as the influence of the studied salts. The model is the first that enables the prediction of adsorption isotherms of proteins on mixed-mode resins in a wide range of technically interesting conditions, accounting for the influence of the ionic strength and four salts of practical relevance.
\end{abstract}

\section{Introduction}

Chromatography is an important separation and purification technique in biotechnological processes. Besides longestablished techniques, such as ion exchange chromatography (IEC), hydrophobic interaction chromatography (HIC), and affinity chromatography (AC), hybrid variants known as mixed-mode chromatography (MMC) exist and have attracted much interest in recent years [1,2]. MMC combines at least two interaction modes, which can act individually or mutually. The most commonly used MMC resins are combinations of IEC and HIC resins [3]. When operated at low ionic strength in solution, the interactions of the target molecules with the ionic ligands of such a MMC resin are usually dominant, i.e., it acts basically as an IEC resin. Higher ionic strengths weaken the ionic interactions and lead to an increased attraction between the target molecules and the hydrophobic part of the resin [4], i.e., it becomes more similar to a HIC resin. Such mixed-mode resins provide wider operating ranges than IEC resins in terms of the salt concentration [5]. This higher salt tolerance compared to IEC may enable direct processing of high conductivity feedstocks [6]. Moreover, MMC can achieve capturing and purification of target molecules from complex solutions in a single process step by simultaneous operation of the different interaction modes $[7,8]$. Mixed-mode resins can offer high binding capacities for proteins [9] as well as improved selectivities compared to single-mode resins $[10,11]$. There are several experimental studies on the application of mixed-mode resins in the literature, e.g., [12-15]. Typically, MMC is thereby applied for challenging separation processes, such as the purification of recombinant proteins, including monoclonal antibodies [15]. 
The conceptual design of chromatographic downstream processes for proteins is complex as the adsorption equilibria are influenced by many parameters, including ionic strength, type of salt present in the solution, temperature, and $\mathrm{pH}$ value, and is usually done by experimental high-throughput screenings (HTS) [16]. The higher complexity of mixedmode resins compared to conventional resins additionally hampers the identification of suitable or even optimized process conditions. The consideration of all relevant parameters by HTS is a time-consuming and cost-intensive procedure. While there are several studies on MMC process development based on HTS, e.g., [17-19], there is still a lack of systematic experimental studies and suitable models to describe the adsorption of proteins in MMC for a broad range of process parameters [20].

Experimental studies on the influence of salts on the adsorption of proteins on mixed-mode resins are mostly limited to sodium chloride, e.g., [21-24]. Only few studies, e.g., $[25,26]$, additionally considered the influence of ammonium sulfate on the protein adsorption for ionic strengths up to $1500 \mathrm{mM}$. Furthermore, attempts to develop mathematical models for the adsorption of proteins on mixed-mode resins are scarce: Ghose et al. [27] and Gao et al. [28] both developed an adsorption isotherm model for MMC based on a modified Langmuir equation. Their models consider the effect of the $\mathrm{pH}$ value and the influence of sodium chloride up to concentrations of $500 \mathrm{mM}$. Similarly, the adsorption isotherm model proposed by Nfor et al. [29], which is based on Mollerup's generalized thermodynamic framework for protein adsorption in IEC and HIC [30-33], describes the influence of sodium chloride concentrations up to $2000 \mathrm{mM}$ and the influence of the $\mathrm{pH}$ value on the adsorption of different proteins. To our knowledge, no model that considers the influence of other salts than sodium chloride on the adsorption of proteins on mixedmode resins has been reported up to now.

In recent studies, our group developed a mathematical model for describing the influence of different salts and salt mixtures on the protein loading of a hydrophobic resin [34-37]. The model is based on a Taylor series expansion in single ion molarities and enables the prediction of equilibrium adsorption isotherms for any mixture of the considered salts up to high ionic strengths. Moreover, this adsorption model was applied for predicting elution profiles of proteins for conceptual process design in HIC [38].

The first objective of the present work is the comprehensive and systematic experimental analysis of the influence of different salts and the ionic strength in industrially relevant ranges on the protein adsorption on a mixed-mode resin. Therefore, the influence of four important salts, namely, sodium chloride, sodium sulfate, ammonium chloride, and ammonium sulfate, on the adsorption of the model protein lysozyme on the mixed-mode resin Toyopearl MX-Trp$650 \mathrm{M}$ at $25^{\circ} \mathrm{C}$ and $\mathrm{pH} 7.0$ was studied experimentally in a systematic way for ionic strengths up to $3000 \mathrm{mM}$. A temperature of $25^{\circ} \mathrm{C}$ and a $\mathrm{pH}$ value of 7.0 were chosen as these values lie well within the ranges in which lysozyme is stable [39-41]. The conditions studied here are therefore typical for adsorption processes with lysozyme in practice. We fur- thermore compare the results of this work with the adsorption of lysozyme on a single-mode HIC resin at the same conditions [35]. However, also studying the influence of different temperatures and $\mathrm{pH}$ values on the adsorption of lysozyme on mixed-mode resins will be of interest in future work. The second objective of the present work is the development of a mathematical model that describes the influence of the four studied salts on the adsorption of lysozyme. Such a model is presented here; it is based on the same principles as our previous model used in [34-37]. However, not the single ions are considered but the salts. The model that is presented here is easy to use and based on only few parameters. It not only enables the correlation of experimental adsorption data but also allows the prediction of unmeasured adsorption isotherms of lysozyme on Toyopearl MX-Trp$650 \mathrm{M}$ for the entire range of technically relevant ionic strengths of the four studied salts at $25^{\circ} \mathrm{C}$ and $\mathrm{pH}$ 7.0. The proposed model approach can also be transferred to other salts, temperatures, $\mathrm{pH}$ values, proteins, or mixed-mode resins in a straightforward manner. It is therefore a valuable tool for the conceptual process design in MMC as it can, e.g., be applied for predicting elution profiles of proteins in MMC.

\section{Materials and Methods}

2.1. Materials. Hen egg white lysozyme (Lys, $M=14.3 \mathrm{kDa}$ ) was obtained from Sigma-Aldrich with a purity over $90 \%$. The mixed-mode resin Toyopearl MX-Trp-650M was obtained from Tosoh Bioscience. Toyopearl MX-Trp-650M combines ionic and hydrophobic interactions as the tryptophan ligand of the resin possesses weak carboxyl cation exchange groups as well as indole hydrophobic functional groups. The salts used for the buffer preparation, namely, monosodium phosphate $\left(\mathrm{NaH}_{2} \mathrm{PO}_{4} \cdot 2 \quad \mathrm{H}_{2} \mathrm{O}\right)$, disodium phosphate $\left(\mathrm{Na}_{2} \mathrm{HPO}_{4} \cdot 2 \mathrm{H}_{2} \mathrm{O}\right)$, sodium chloride $(\mathrm{NaCl})$, sodium sulfate $\left(\mathrm{Na}_{2} \mathrm{SO}_{4}\right)$, ammonium chloride $\left(\mathrm{NH}_{4} \mathrm{Cl}\right)$, and ammonium sulfate $\left(\left(\mathrm{NH}_{4}\right)_{2} \mathrm{SO}_{4}\right)$, were of analytical grade. Ammonium chloride was obtained from Bernd Kraft; all other salts were obtained from Carl-Roth. $1 \mathrm{~N}$ sodium hydroxide $(\mathrm{NaOH})$ and $1 \mathrm{~N}$ hydrochloric acid $(\mathrm{HCl})$, which were used for the adjustment of the $\mathrm{pH}$ value of the buffer solutions, were obtained from Carl-Roth. For all solutions, high-purity water, produced with a Milli-Q system from Merck Millipore, was used as solvent.

2.2. Batch Adsorption Experiments. Batch adsorption experiments were carried out on a fully automated liquid handling station Freedom EVO 200 from Tecan. The equilibrium measurements were carried out with $50.9 \mu \mathrm{l}$ resin, prepared with a Media Scout ResiQuot device from Atoll, and $500 \mu \mathrm{l}$ lysozyme stock solution in $96 \times 1.2 \mathrm{ml}$ Riplate deepwell plates from Ritter. Preliminary lysozyme solutions were prepared gravimetrically with an AX205 scale from Mettler Toledo by dissolving lysozyme in $25 \mathrm{mM}$ sodium phosphate buffer. Prior to the addition of lysozyme, the $\mathrm{pH}$ value of the buffer was adjusted to 7.0 with $1 \mathrm{~N}$ sodium hydroxide or $1 \mathrm{~N}$ hydrochloric acid. The $\mathrm{pH}$ value was measured with a $780 \mathrm{pH}$ meter from Metrohm. Besides the lysozyme 
solutions, additional solutions of the studied salt $(\mathrm{NaCl}$, $\mathrm{Na}_{2} \mathrm{SO}_{4}, \mathrm{NH}_{4} \mathrm{Cl}$, or $\left.\left(\mathrm{NH}_{4}\right)_{2} \mathrm{SO}_{4}\right)$ were prepared gravimetrically using the same scale by dissolving the salts in $25 \mathrm{mM}$ sodium phosphate buffer. The $\mathrm{pH}$ values of the salt solutions were adjusted as described above. The lysozyme stock solutions for the adsorption experiments were prepared by mixing the preliminary lysozyme solution and salt solution in a 1:1 $(v / v)$ ratio yielding ionic strengths of the studied salts varying between $0 \mathrm{mM}$ and $3000 \mathrm{mM}$ in the final lysozyme stock solution. The temperature during the adsorption experiments was always $25^{\circ} \mathrm{C}$. The equilibration time on a tempered shaker from Inheco was $6 \mathrm{~h}$. The lysozyme concentration in solution after equilibration was analyzed by UV absorption at $280 \mathrm{~nm}$ using an Infinite M200 plate reader from Tecan. As blank value, the same procedure was performed three times with lysozyme-free solutions for each studied salt and the mean value of these measurements was used for calibrating the concentration determination of the lysozyme-containing solutions. The equilibrium experiments and the analytics were performed as described in detail by Werner et al. [42]. The relative error of the equilibrium loading of the resin determined in these experiments is about $10 \%$, except for very small loadings [42].

2.3. Correlation of Individual Adsorption Isotherms. The experimental results of the adsorption isotherms were correlated with the semi-empirical approach of Oberholzer and Lenhoff $[43,44]$ :

$$
c_{\mathrm{Lys}}=\frac{q_{\mathrm{Lys}}}{K^{\text {ads }}} \cdot \exp \left[\beta \cdot \sqrt{\frac{q_{\mathrm{Lys}}}{q_{0}}} \cdot \exp \frac{-\gamma}{\sqrt{q_{\mathrm{Lys}} / \mathrm{q}_{0}}}\right],
$$

where $c_{\mathrm{Lys}}$ is the lysozyme concentration in solution, $q_{\mathrm{Lys}}$ is the lysozyme loading of the resin, and $K^{\text {ads }}$ is the adsorption equilibrium constant. $\beta$ and $\gamma$ are lumped fitting parameters, which were made dimensionless by introducing $q_{0}=1 \mathrm{mg}$ $\mathrm{ml}^{-1}$. Equation (1) was only used here for correlating individual isotherms. This could have been done with any mathematical correlation that yields an adequate description of the data without substantially influencing the results of this work.

2.4. Data Processing. In the present work, MATLAB was used for all data processing and modeling steps. For better comparability of the influence of the four studied salts $(\mathrm{NaCl}$, $\mathrm{Na}_{2} \mathrm{SO}_{4}, \mathrm{NH}_{4} \mathrm{Cl}$, and $\left.\left(\mathrm{NH}_{4}\right)_{2} \mathrm{SO}_{4}\right)$, the results are discussed in terms of ionic strength $I$, which is defined using the molarities of the ions. The small concentration of buffer salts $(c=25 \mathrm{mM})$ that was present in all solutions was not taken into account for calculating the ionic strength throughout this work.

\section{Results and Discussion}

3.1. Experimental Adsorption Isotherms. Figure 1 shows the experimental equilibrium adsorption data obtained in this work for solutions containing sodium chloride, sodium sulfate, ammonium chloride, or ammonium sulfate together with the corresponding individual correlations, cf. Equation (1). Lysozyme carries a positive net charge at the studied $\mathrm{pH}$ value of 7.0 [41]. Therefore, as expected, the highest lysozyme loadings were observed when no salt was added to the solution $(I=0 \mathrm{mM})$, i.e., if pure $25 \mathrm{mM}$ sodium phosphate buffer was used as solvent. The positively charged lysozyme adsorbs on the negatively charged carboxyl groups of the mixed-mode resin. Shielding effects of salts are nearly negligible as only very small ion concentrations of the buffer salts are present in the solution here. The addition of all studied salts leads to a decrease of the lysozyme loading with increasing ionic strength up to approx. $1000 \mathrm{mM}$. This behavior can be explained by the shielding of the negatively charged groups of the resin, i.e., the cation exchange part of the resin, by the cations in the solution as well as by the shielding of the positively charged sites on the lysozyme by the anions. The cations compete with lysozyme for the negatively charged positions of the resin. With increasing ionic strength, the cation exchange sites of the mixed-mode resin are increasingly occupied by the present cations, such that these sites are not accessible for the adsorption of lysozyme anymore. Moreover, the shielding of lysozyme by anions decreases the attraction between lysozyme and the negatively charged resin. Overall, at low ionic strengths, the cation exchange mechanism is the dominant contribution to the capacity of the mixed-mode resin, but this contribution decreases with increasing ionic strength. Very high ionic strengths lead to a complete occupation of the cation exchange sites of the resin with the cations in solution, such that ionic interactions between lysozyme and the resin are less pronounced in this regime. At the same time, an increase in ionic strength results in the exposure of hydrophobic regions on the lysozyme surface. The hydrate shells surrounding the lysozyme molecules are degraded by the ions in solution interacting with the surrounding water molecules, also known as salting-out effect [45]. Hence, the exposure of the hydrophobic surface regions of lysozyme can lead to an enhanced interaction with the hydrophobic indole groups of the resin. Therefore, at high ionic strengths, namely, above about $I=1000 \mathrm{mM}$, one can expect that the lysozyme loading increases with increasing ionic strength due to favored hydrophobic interactions. However, the lysozyme loadings show no significant dependence on $I$ : all differences among the experimental data taken in that region are within the experimental uncertainties. This was observed for all investigated salts, cf. Figure 1. This behavior can be attributed to the superposition of the two discussed opposing effects: the increasing ionic strength leads to a weakening of the cation exchange mechanism of the adsorption whereas it favors the hydrophobic interactions by a salting-out effect, which leads to a better adsorption. For all salts, a significantly higher capacity was found in the cation exchange region (at very low $I$ ) than in the hydrophobic interaction region (at high $I$ ), which is in agreement with other reports on mixed-mode resins in the literature $[25,28,29]$. Furthermore, the adsorption isotherms tend to be almost linear in the hydrophobic interaction region whereas a considerable curvature was observed in the cation exchange region for all studied salts. 


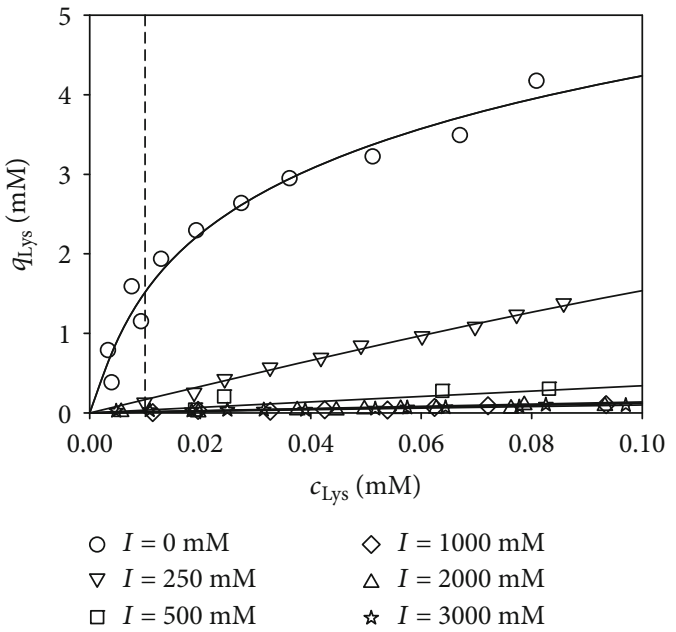

(a) $\mathrm{NaCl}$

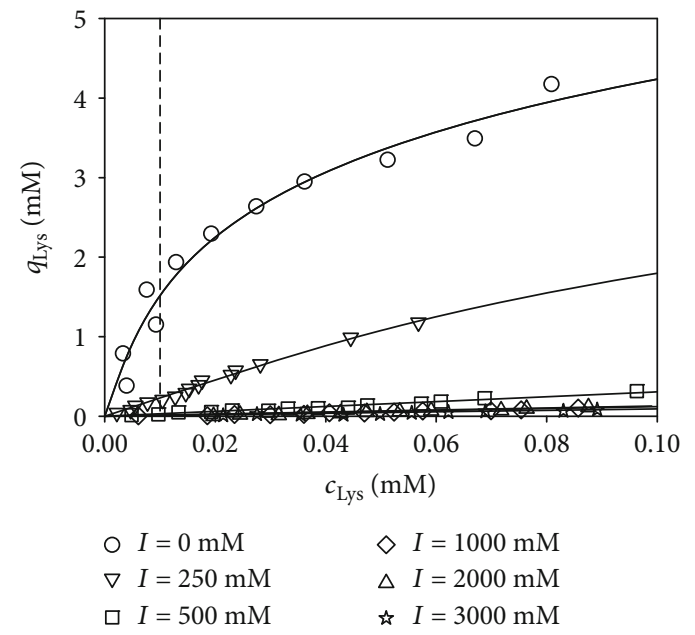

(c) $\mathrm{NH}_{4} \mathrm{Cl}$

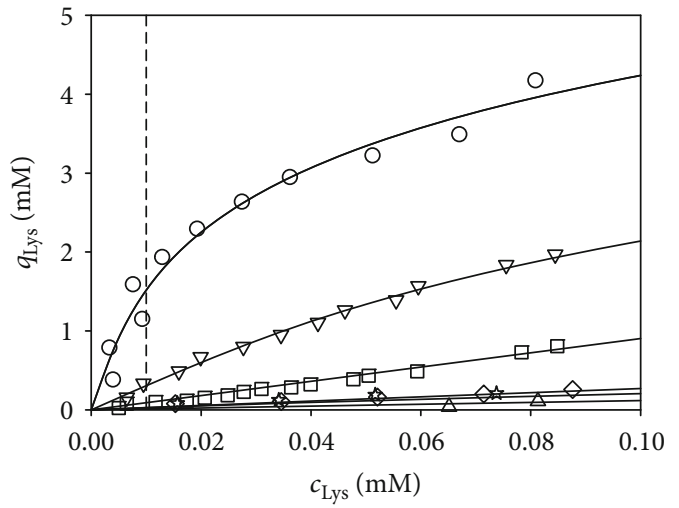

$$
\begin{array}{ll}
\circ I=0 \mathrm{mM} & \diamond I=1000 \mathrm{mM} \\
\nabla I=250 \mathrm{mM} & \Delta I=2000 \mathrm{mM} \\
\square I=500 \mathrm{mM} & \text { औ } I=3000 \mathrm{mM}
\end{array}
$$

(b) $\mathrm{Na}_{2} \mathrm{SO}_{4}$

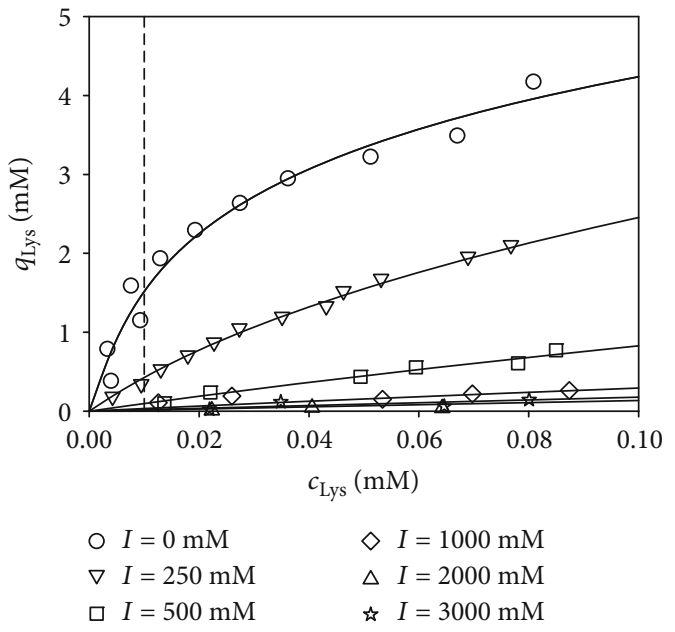

(d) $\left(\mathrm{NH}_{4}\right)_{2} \mathrm{SO}_{4}$

FIGURE 1: Experimental equilibrium adsorption isotherms (symbols) of lysozyme on Toyopearl MX-Trp-650M at $\mathrm{pH} 7.0$ and $25^{\circ} \mathrm{C}$ for different ionic strengths $I$ of (a) sodium chloride, (b) sodium sulfate, (c) ammonium chloride, and (d) ammonium sulfate and corresponding individual correlations (lines), cf. Equation (1). Data for $I=1500 \mathrm{mM}$ and $I=2500 \mathrm{mM}$, which were also measured in the present work, are not depicted here for improved clarity.

In Figure 2, the experimental results for all studied salts at a constant ionic strength of $250 \mathrm{mM}$ are depicted.

Solutions containing sulfate ions show higher lysozyme loadings than solutions containing chloride ions. The rather large size of sulfate ions might hamper the accumulation around the positively charged lysozyme and thereby lead to a weaker shielding effect compared to the rather small chloride ions. Hence, in solutions containing sulfate ions, lysozyme adsorbs significantly stronger at the ion exchange ligands than it adsorbs in solutions of the same ionic strength but containing chloride ions. The highest loadings were observed for ammonium sulfate, the lowest for sodium chloride. This was found for all studied ionic strengths for which significant differences between the lysozyme loadings were obtained, i.e., for rather low ionic strengths up to approx. $1000 \mathrm{mM}$, at which ionic adsorption is assumed predominant. This agrees well with the previous presumption: ammonium ions are significantly larger than sodium ions and, hence, can be expected to lead to a weaker shielding effect than sodium ions. The differences in the influence of sodium chloride and ammonium sulfate on the lysozyme loading of Toyopearl MX-Trp-650M correspond well with the findings of Wu et al. [25], who studied the influence of these two salts on the loading of the same mixed-mode resin with human serum albumin (HSA).

The results of the correlation of the individual experimental isotherms with Equation (1) are summarized in Table S.1 in the Supplementary Materials. For describing the influence of the studied salts and the ionic strength on the adsorption of lysozyme on the studied mixed-mode resin, we have developed a model along the lines of an approach previously introduced by our group [34-37].

3.2. Model of Loading as a Function of Ionic Strength. For a better comparability of the adsorption of lysozyme for the different ionic strengths and studied salts, the adsorption 


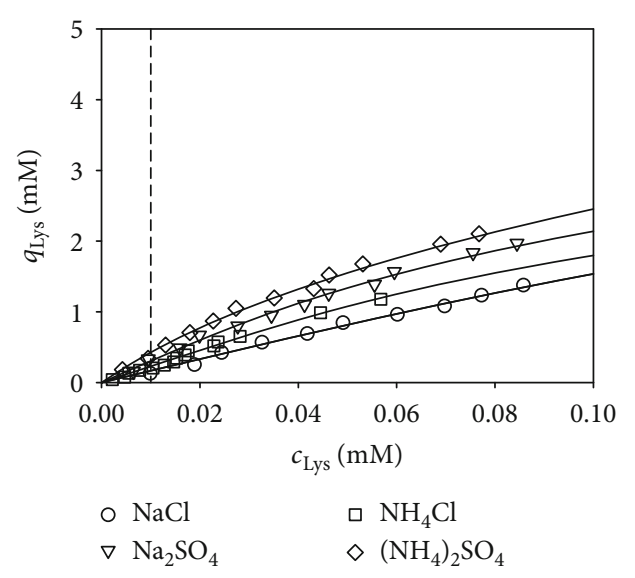

FIgURE 2: Experimental equilibrium adsorption isotherms (symbols) of lysozyme on Toyopearl MX-Trp-650M at $\mathrm{pH} 7.0$, $25^{\circ} \mathrm{C}$, and $I=250 \mathrm{mM}$ for all studied salts and corresponding individual correlations (lines), cf. Equation (1).

isotherm data were reduced in the same way as in our previous work [34]: the lysozyme loading $q_{\text {Lys }}$ of the mixed-mode resin, as given by the individual correlations, cf. Equation (1), at a constant lysozyme concentration $c_{\text {Lys }}$ was considered and compared for the studied conditions. As an example, the results for the loading $q_{\mathrm{Lys}}$ for $c_{\mathrm{Lys}}=0.01 \mathrm{mM}$ (cf. the vertical dashed lines in Figures 1 and 2) as a function of the ionic strength $I$ are shown in Figure 3 for all studied salts.

As described before, we could expect that the lysozyme loading decreases in the cation exchange region due to the cations in solution competing with the lysozyme molecules for the negatively charged positions of the resin, whereas the loading increases in the hydrophobic interaction region with increasing ionic strength due to, among others, the salting-out effect. However, the experimental results indicate an exponential decay of $q_{\mathrm{Lys}}\left(c_{\mathrm{Lys}}=0.01 \mathrm{mM}\right)$ with increasing ionic strength up to approx. $I=1000 \mathrm{mM}$ and a rather constant behavior of $q_{\text {Lys }}\left(c_{\text {Lys }}=0.01 \mathrm{mM}\right)$ at a low level for $I>1000 \mathrm{mM}$ for all four salts.

The exponential decay in the cation exchange region, where high lysozyme loadings were observed, indicates that the effect of adding a certain amount of salt on the adsorption is directly proportional to the amount of salt already present in the solution in this region. Here, the shielding effect of additional ions is strong if only few ions are already present in the solution, whereas it is weaker if there are already many ions in the solution. It can be speculated that the finding also holds for other proteins and MMC resins, and, more importantly, that it also holds for IEC resins. Results from other studies, e.g., [21, 26, 46-48], support this assumption.

While basically no protein adsorption can be expected on a single-mode IEC resin at high ionic strengths [48], the results of the present work demonstrate that there is at least some adsorption of lysozyme in the entire studied range of ionic strengths (up to $3000 \mathrm{mM}$ ). This is shown in Figure 4, which constitutes enlarged representations of the results shown in Figure 3. Furthermore, in Figure 4, results for the adsorption of lysozyme on a single-mode HIC resin from a

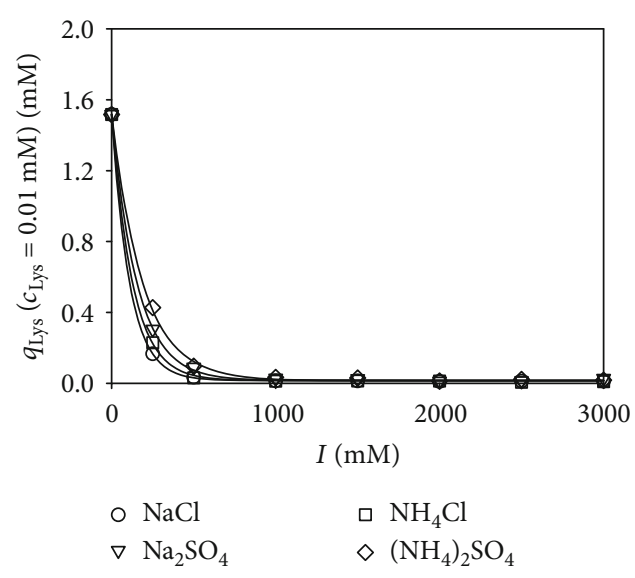

FIgURE 3: Lysozyme loading $q_{\text {Lys }}$ of Toyopearl MX-Trp-650M at $c_{\text {Lys }}=0.01 \mathrm{mM}, \mathrm{pH} 7.0$, and $25^{\circ} \mathrm{C}$ for all studied salts as a function of ionic strength $I$. Symbols: experimental results (correlated with Equation (1)). Lines: correlations with Equation (2).

previous work of our group [35] are shown. For all salts except for sodium chloride, at high ionic strengths ( $I>2000 \mathrm{mM})$, the adsorption of lysozyme on the studied mixed-mode resin is comparable to the adsorption on the pure HIC resin. This demonstrates the salt-tolerant nature of the mixed-mode resin.

Based on the experimental results, an exponential correlation was used in this work for describing the dependence of the lysozyme loading $q_{\mathrm{Lys}}$ at constant lysozyme concentration $c_{\text {Lys }}$ on the ionic strength $I$ in solution for each salt $S$ :

$$
\frac{q_{\mathrm{Lys}}\left(c_{\mathrm{Lys}}=\text { const. }\right)}{\mathrm{mM}}=k_{0}-k_{\mathrm{F}}+k_{\mathrm{F}} \cdot \exp \left(-k_{S} \cdot \frac{I}{1000 \mathrm{mM}}\right),
$$

where $k_{0}, k_{\mathrm{F}}$, and $k_{S}$ are model parameters. If no salt is present in the solution, i.e., for $I=0 \mathrm{mM}, q_{\mathrm{Lys}}\left(c_{\mathrm{Lys}}=\right.$ const. $)$ equals $k_{0}$. For very high salt concentrations, the influence of salt type and concentration vanishes, cf. Figure 3 , and $q_{\text {Lys }}\left(c_{\text {Lys }}=\right.$ const. $)$ equals the difference $k_{0}-k_{\mathrm{F}}$. Hence, the parameters $k_{0}$ and $k_{\mathrm{F}}$ do not depend on the salt $S$ and its concentration in solution. The parameter $k_{S}$, in contrast, is salt-specific and describes how strong a specific salt $S$ influences the adsorption of lysozyme on the mixed-mode resin. The resulting parameters obtained by fitting Equation (2) to the data of this work are reported in Table S.2 in the Supplementary Materials. Sodium chloride shows the greatest effect on the loading in the cation exchange region, which might be caused by a strong shielding effect of the comparably small sodium and chloride ions, leading to a large value of $k_{\mathrm{NaCl}}$ and therefore to the smallest adsorption of lysozyme with sodium chloride compared to the other salts, cf. Equation (2). By contrast, ammonium sulfate has the smallest effect, which might be caused by a rather weak shielding effect of the comparably large ammonium and sulfate ions, leading to a 


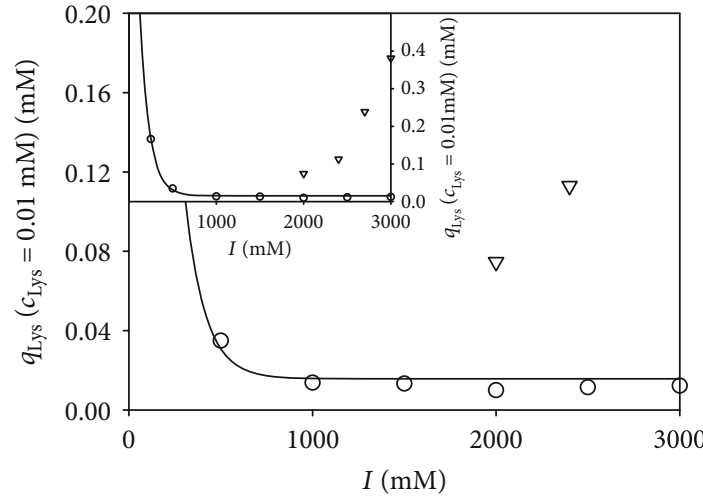

O MMC resin (this work) $\nabla$ HIC resin [35]

(a) $\mathrm{NaCl}$

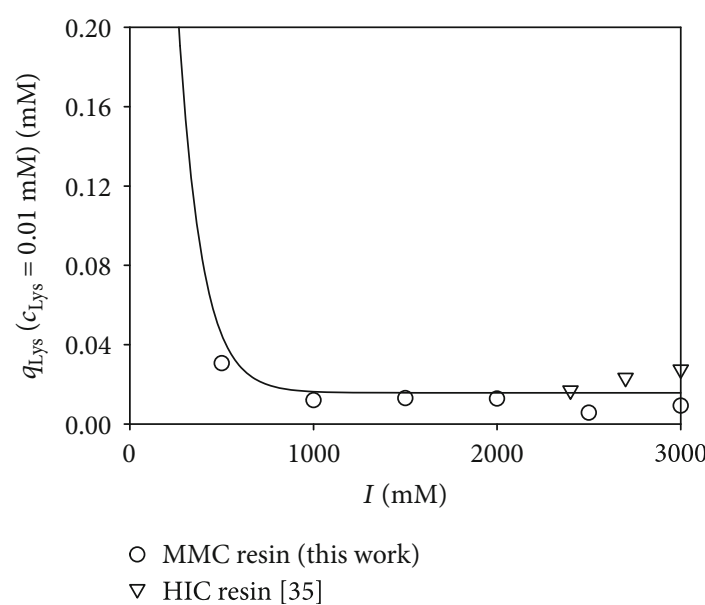

(c) $\mathrm{NH}_{4} \mathrm{Cl}$

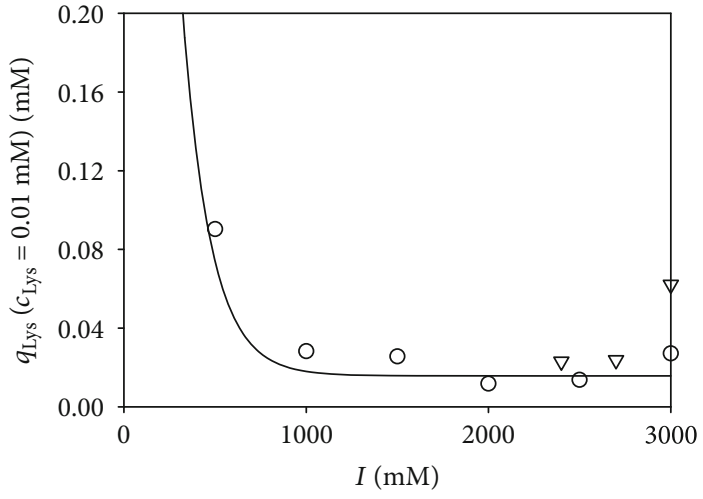

O MMC resin (this work)

$\nabla$ HIC resin [35]

(b) $\mathrm{Na}_{2} \mathrm{SO}_{4}$

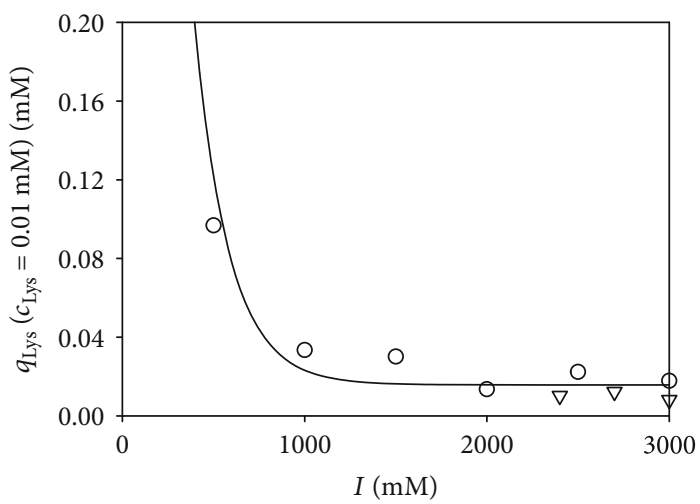

O MMC resin (this work)

$\nabla$ HIC resin [35]

(d) $\left(\mathrm{NH}_{4}\right)_{2} \mathrm{SO}_{4}$

Figure 4: Lysozyme loading $q_{\text {Lys }}$ of the MMC resin Toyopearl MX-Trp-650M and the single-mode HIC resin Toyopearl PPG-600M at $c_{\text {Lys }}=0.01 \mathrm{mM}, \mathrm{pH} 7.0$, and $25^{\circ} \mathrm{C}$ for all studied salts as a function of ionic strength $I$. Symbols: experimental results. Lines: correlations of the MMC results with Equation (2). In order to display all experimental HIC data for sodium chloride, an additional inset figure with a larger scale is included.

small value of $k_{\left(\mathrm{NH}_{4}\right)_{2} \mathrm{SO}_{4}}$ and therefore to the strongest adsorption of lysozyme with ammonium sulfate compared to the other salts, cf. Equation (2). Hence, the larger the value of $k_{S}$, the stronger is the negative effect of the respective salt $S$ on the adsorption of lysozyme on the MMC resin and therefore the lower is the adsorption of lysozyme at a specific ionic strength.

As depicted in Figures 3 and 4, Equation (2) represents the dependence of the lysozyme loading on the ionic strength very well for $c_{\text {Lys }}=0.01 \mathrm{mM}$ and all four studied salts: the correlations with Equation (2) (lines) reproduce the data from the individual adsorption isotherms (symbols) within their uncertainty. The procedure described above was carried out for lysozyme concentrations in the interval $c_{\mathrm{Lys}}=$ $(0.01-0.1) \mathrm{mM}$ with a step size of $0.01 \mathrm{mM}$ and additionally for $c_{\text {Lys }}=0.001 \mathrm{mM}$ to obtain information on highly diluted solutions, for which adsorption isotherms are usually linear and can be described by the adsorption equilibrium constant $K^{\text {ads }}$ alone. At high lysozyme concentrations like $c_{\text {Lys }}=$
$0.1 \mathrm{mM}$, the equilibrium loading of the mixed-mode resin is nearly reached in some cases. Figure S.1 in the Supplementary Materials illustrates exemplarily the results for $c_{\mathrm{Lys}}=0.001 \mathrm{mM}$ and $c_{\mathrm{Lys}}=0.1 \mathrm{mM}$. Good correlations with Equation (2) were found for all lysozyme concentrations. The results for the parameters $k_{0}, k_{\mathrm{F}}$, and $k_{S}$ obtained from fitting Equation (2) for $c_{\mathrm{Lys}}=(0.001-0.1) \mathrm{mM}$ are shown in Table S.2 in the Supplementary Materials.

3.3. Dependence of Model Parameters on Lysozyme Concentration $c_{L y s}$. The results presented in Table S.2 in the Supplementary Materials indicate a dependence of the parameters $k_{0}, k_{\mathrm{F}}$, and $k_{\mathrm{S}}$ on the lysozyme concentration $c_{\text {Lys. }}$. This is also illustrated in Figure 5.

If no salt is present in the solution, i.e., for $I=0 \mathrm{mM}$, the lysozyme loading $q_{\mathrm{Lys}}\left(c_{\mathrm{Lys}}=\right.$ const. $)$ is given by $k_{0}$, cf. Equation (2). Hence, $k_{0}\left(c_{\text {Lys }}\right)$ equals the equilibrium adsorption isotherm of lysozyme if pure $25 \mathrm{mM}$ sodium phosphate buffer without additional salts is used as solvent. Therefore, 


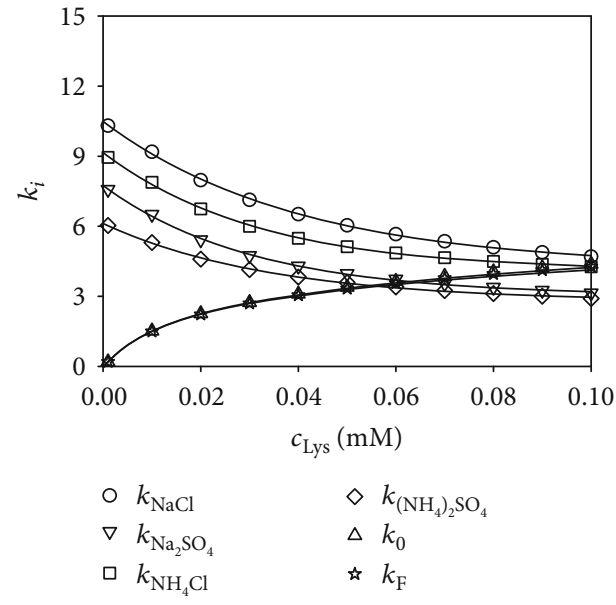

FIgURe 5: Parameters $k_{0}, k_{\mathrm{F}}$, and $k_{S}$ of Equation (2) for correlating the dependence of the lysozyme loading on the ionic strength, cf. Table S.2 in the Supplementary Materials, plotted over the lysozyme concentration $c_{\text {Lys }}$ for all studied salts. Symbols: experimental results (correlated with Equation (2)). Lines: correlations with Equation (3), (4), or (5).

the dependence of $k_{0}$ on $c_{\text {Lys }}$ was modeled with the semiempirical correlation function of Oberholzer and Lenhoff, cf. Equation (1), which was already used for correlating the individual isotherms in this work:

$$
\frac{c_{\mathrm{Lys}}}{\mathrm{mM}}=\frac{k_{0}}{a_{0}^{(1)}} \cdot \exp \left[a_{0}^{(2)} \cdot \sqrt{k_{0}} \cdot \exp \frac{-a_{0}^{(3)}}{\sqrt{k_{0}}}\right],
$$

where $a_{0}^{(1)}, a_{0}^{(2)}$, and $a_{0}^{(3)}$ correspond to the parameters $K^{\text {ads }}, \beta$, and $\gamma$ from Equation (1), respectively. The obtained parameters $a_{0}^{(1)}, a_{0}^{(2)}$, and $a_{0}^{(3)}$ are summarized in Table 1 .

At very high ionic strengths, the lysozyme loading $q_{\mathrm{Lys}}\left(c_{\mathrm{Lys}}=\right.$ const. $)$ is described by the difference $k_{0}-k_{\mathrm{F}}$ in Equation (2). At these conditions, the equilibrium adsorption isotherms show a rather linear behavior as illustrated in Figure 1. Therefore, a linear correlation was introduced for the dependence of $k_{0}-k_{\mathrm{F}}$ on $c_{\mathrm{Lys}}$ here:

$$
k_{0}-k_{\mathrm{F}}=a_{\mathrm{F}}^{(1)} \cdot \frac{c_{\mathrm{Lys}}}{\mathrm{mM}},
$$

where $a_{\mathrm{F}}^{(1)}$ denotes the adsorption equilibrium constant of the considered linear isotherms at high ionic strengths and was fitted to the data for $k_{0}$ and $k_{\mathrm{F}}$ shown in Figure 5, cf. also Table S.2 in the Supplementary Materials. The obtained number for $a_{\mathrm{F}}^{(1)}$ is given in Table 1. The results for $k_{\mathrm{F}}$ depicted in Figure 5 almost coincide with those for $k_{0}$. This is due to the rather small numbers of the difference $k_{0}-k_{\mathrm{F}}$ compared to the numbers of $k_{0}$, i.e., the small lysozyme loadings at high ionic strengths compared to those for $I=0 \mathrm{mM}$.

The results in Figure 5 indicate an exponential dependence of the salt-dependent parameters $k_{S}$ on $c_{\mathrm{Lys}}$ for all four
TABLE 1: Parameters describing the dependence of $k_{0}, k_{\mathrm{F}}$, and $k_{S}$ on $c_{\text {Lys }}$, cf. Equations (3)-(5).

\begin{tabular}{lccc}
\hline & $a_{i}^{(1)}$ & $a_{i}^{(2)}$ & $a_{i}^{(3)}$ \\
\hline$k_{0}$ & 221.65 & 3.06 & 2.88 \\
$k_{\mathrm{F}}$ & 1.11 & - & - \\
$k_{\mathrm{NaCl}}$ & 10.49 & 6.26 & 25.03 \\
$k_{\mathrm{Na}_{2} \mathrm{SO}_{4}}$ & 7.74 & 4.72 & 32.67 \\
$k_{\mathrm{NH}_{4} \mathrm{Cl}}$ & 9.16 & 5.08 & 31.56 \\
$k_{\left(\mathrm{NH}_{4}\right)_{2} \mathrm{SO}_{4}}$ & 6.12 & 3.34 & 28.96 \\
\hline
\end{tabular}

salts. Therefore, a correlation function similar to Equation (2) was deployed for describing $k_{S}$ for each salt $S$ as a function of $c_{\text {Lys }}$ :

$$
k_{S}=a_{S}^{(1)}-a_{S}^{(2)}+a_{S}^{(2)} \cdot \exp \left(-a_{S}^{(3)} \cdot \frac{c_{\mathrm{Lys}}}{\mathrm{mM}}\right),
$$

where $a_{S}^{(1)}, a_{S}^{(2)}$, and $a_{S}^{(3)}$ are the salt-dependent model parameters, which were fitted to the data for $k_{S}$, cf. Table S.2 in the Supplementary Materials and symbols in Figure 5. The obtained parameters are summarized in Table 1. As represented by the lines in Figure 5, an excellent correlation of $k_{S}$ as a function of $c_{\text {Lys }}$ was obtained with Equation (5). If no lysozyme is present in the solution, i.e., $c_{\mathrm{Lys}}=0 \mathrm{mM}, k_{S}$ equals the parameter $a_{S}^{(1)}$. For highly concentrated lysozyme solutions, $k_{S}$ is given by the difference $a_{S}^{(1)}-a_{S}^{(2)}$. The parameter $a_{S}^{(3)}$ describes the exponential decay of $k_{S}$ over the lysozyme concentration.

The lines in Figure 5 denote the model results for the dependence of $k_{0}, k_{\mathrm{F}}$, and $k_{S}$ on $c_{\mathrm{Lys}}$ obtained with Equation (3), (4), or (5), respectively. An excellent description for all parameters was obtained.

3.4. Prediction of Equilibrium Adsorption Isotherms. Inserting Equations (3)-(5) in Equation (2) yields:

$\frac{q_{\mathrm{Lys}}\left(c_{\mathrm{Lys}}\right)}{\mathrm{mM}}=k_{0}\left(c_{\mathrm{Lys}}\right)-k_{\mathrm{F}}\left(c_{\mathrm{Lys}}\right)+k_{\mathrm{F}}\left(c_{\mathrm{Lys}}\right) \cdot \exp \left(-k_{S}\left(c_{\mathrm{Lys}}\right) \cdot \frac{I}{1000 \mathrm{mM}}\right)$.

Equation (6) can be considered as a new adsorption isotherm model. Using only the parameters from Table 1, Equation (6) enables the prediction of adsorption isotherms for lysozyme on the mixed-mode resin Toyopearl MX-Trp-650M at $25^{\circ} \mathrm{C}$ and $\mathrm{pH} 7.0$ under the influence of sodium chloride, sodium sulfate, ammonium chloride, or ammonium sulfate for ionic strengths up to $I=3000 \mathrm{mM}$.

In Figure 6, isotherms obtained with this model (lines) are compared to the experimental data obtained in this work (symbols).

For all four salts and all considered ionic strengths, a very good agreement between model and experimental 


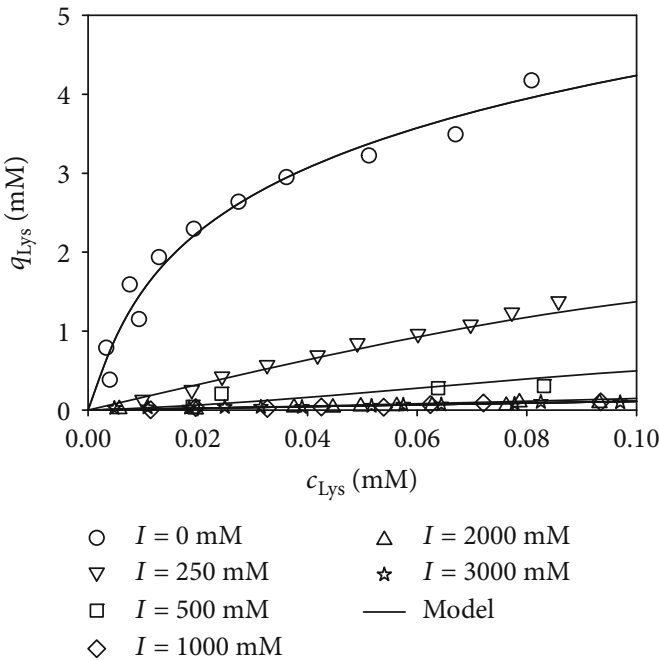

(a) $\mathrm{NaCl}$

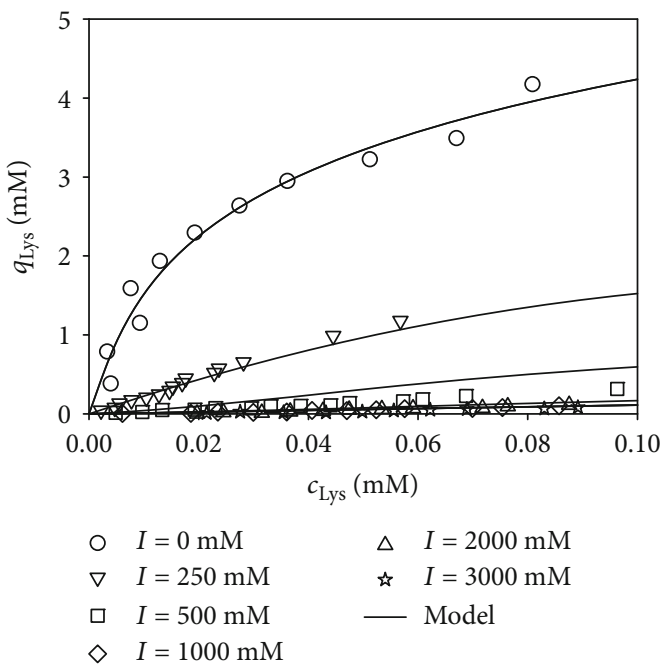

(c) $\mathrm{NH}_{4} \mathrm{Cl}$

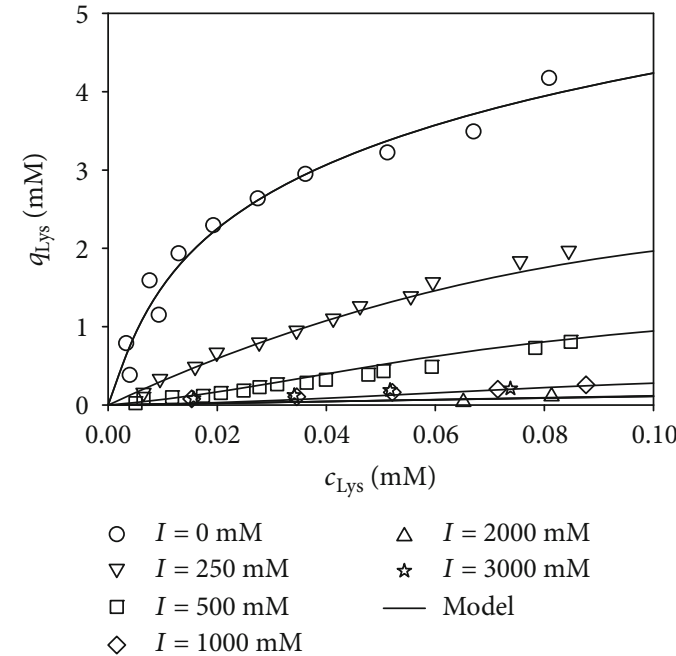

(b) $\mathrm{Na}_{2} \mathrm{SO}_{4}$

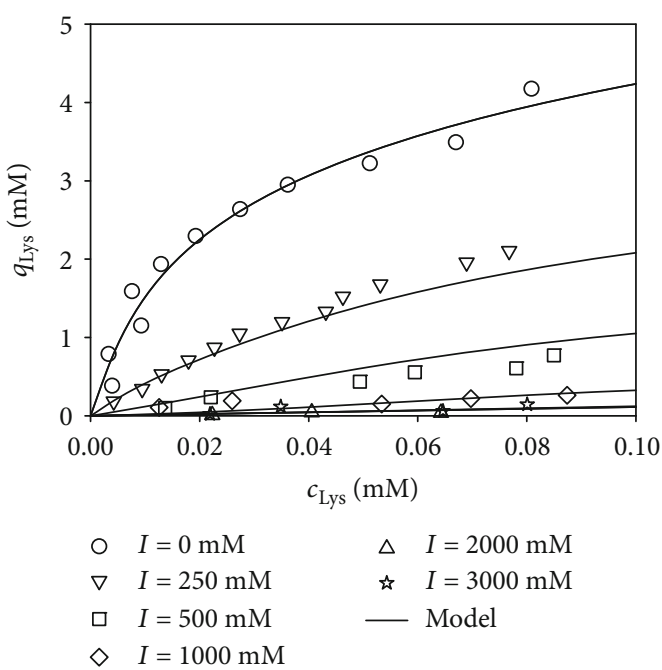

(d) $\left(\mathrm{NH}_{4}\right)_{2} \mathrm{SO}_{4}$

Figure 6: Comparison of modeled equilibrium adsorption isotherms (lines) to experimental data (symbols) for lysozyme on Toyopearl MX-Trp-650M at pH 7.0 and $25^{\circ} \mathrm{C}$ for different ionic strengths $I$ of (a) sodium chloride, (b) sodium sulfate, (c) ammonium chloride, and (d) ammonium sulfate. Data for $I=1500 \mathrm{mM}$ and $I=2500 \mathrm{mM}$, which were also measured in the present work, are not depicted here for improved clarity.

data was observed. The model correctly describes the significantly higher lysozyme loadings at lower ionic strengths due to strong ionic interactions and the rather low loadings at higher ionic strengths that can be attributed to occupied cation exchange sites of the resin and enhanced hydrophobic interactions, which are in general weaker than ionic interactions, for all salts. For ionic strengths between $1000 \mathrm{mM}$ and $3000 \mathrm{mM}$, the model shows no significant dependence of the adsorption isotherms on the ionic strength or salt. Additionally, the model correctly describes the increasing linearity of the adsorption isotherms with increasing ionic strength. Hence, the proposed model can be used for the prediction of adsorption isotherms within the trained parameter range and therefore constitutes the basis of simulating column experiments and elution profiles with mixed-mode resins.

\section{Conclusions}

In the present work, we have systematically studied the influence of different salts and the ionic strength on the adsorption of lysozyme on the mixed-mode resin Toyopearl MX-Trp$650 \mathrm{M}$ at $\mathrm{pH} 7.0$ and $25^{\circ} \mathrm{C}$. Substantial adsorption of lysozyme was found for the entire range of studied ionic strengths, which demonstrates the salt tolerance of the mixed-mode resin. For all studied salts (sodium chloride, sodium sulfate, ammonium chloride, and ammonium sulfate), the lysozyme loading of the resin decreases exponentially with increasing ionic strength up to approx. $1000 \mathrm{mM}$. This observation can be explained by physical considerations: the effect of adding a certain amount of salt is directly proportional to the amount of salt already present in the solution. Hence, at low ionic strengths, where the 
cation exchange mechanism of the mixed-mode resin is dominant, each ion in solution has a stronger influence on the adsorption by shielding the ionic ligands of the resin than at higher ionic strengths. For a constant ionic strength in this region, the strongest influence was found for sodium chloride, which might be explained by a strong shielding effect of the rather small sodium and chloride ions. We speculate that the observed exponential dependence of the protein loading on the ionic strength is generic for chromatography in which ion exchange mechanisms are dominant. At higher ionic strengths, i.e., from approx. $1000 \mathrm{mM}$ up to $3000 \mathrm{mM}$, where hydrophobic interactions are predominant, no significant influence of different salts or the ionic strength was observed. For all salts except sodium chloride, the found adsorption in this region is similar to the adsorption of lysozyme on a single-mode HIC resin that was studied in a previous work. Rather linear adsorption isotherms were observed in the hydrophobic interaction region.

We furthermore present a mathematical model for the adsorption of lysozyme on Toyopearl MX-Trp-650M. The model successfully describes the influence of the different studied salts, the ionic strength, and the lysozyme concentration in solution on the lysozyme loading. The model allows the prediction of equilibrium adsorption isotherms for a wide range of process parameters, e.g., for in principle any practically relevant ionic strength, including the transition region from the cation exchange region to the hydrophobic interaction region. Hence, also adsorption isotherms for not studied conditions can be predicted with the presented model approach based on only few parameters. The proposed model approach can be transferred to other salts, temperatures, $\mathrm{pH}$ values, proteins, or mixed-mode resins in a straightforward manner and ultimately be applied for simulation, conceptual design, and optimization of separation processes of proteins with mixed-mode chromatography.

\section{Data Availability}

The adsorption data used to support the findings of this study are included within the Supplementary Materials.

\section{Conflicts of Interest}

The authors declare no potential conflicts of interest with respect to the research, authorship, and/or publication of this article.

\section{Supplementary Materials}

Additional model results and parameters are included within the Supplementary Materials. (Supplementary Materials)

\section{References}

[1] K. Zhang and X. Liu, "Mixed-mode chromatography in pharmaceutical and biopharmaceutical applications," Journal of Pharmaceutical and Biomedical Analysis, vol. 128, pp. 73-88, 2016.

[2] K. Kallberg, H.-O. Johansson, and L. Bulow, "Multimodal chromatography: an efficient tool in downstream processing of proteins," Biotechnology Journal, vol. 7, no. 12, pp. 14851495, 2012.

[3] D. Gao, D.-Q. Lin, and S.-J. Yao, "Mechanistic analysis on the effects of salt concentration and $\mathrm{pH}$ on protein adsorption onto a mixed-mode adsorbent with cation ligand," Journal of Chromatography B, vol. 859, no. 1, pp. 16-23, 2007.

[4] D. Gao, D.-Q. Lin, and S.-J. Yao, "Protein adsorption kinetics of mixed-mode adsorbent with benzylamine as functional ligand," Chemical Engineering Science, vol. 61, no. 22, pp. 7260-7268, 2006.

[5] K. A. Kaleas, C. H. Schmelzer, and S. A. Pizarro, "Industrial case study: Evaluation of a mixed-mode resin for selective capture of a human growth factor recombinantly expressed in $E$. coli," Journal of Chromatography A, vol. 1217, no. 2, pp. 235-242, 2010.

[6] M.-H. Lu, D.-Q. Lin, Y.-C. Wu, J.-X. Yun, L.-H. Mei, and S.-J. Yao, "Separation of nattokinase from Bacillus subtilis fermentation broth by expanded bed adsorption with mixed-mode adsorbent," Biotechnology and Bioprocess Engineering, vol. 10, no. 2, pp. 128-135, 2005.

[7] A. Lees, A. Topping, A. Razzaq, K. Reiter, and A.-L. Acosta, "Purifying a recalcitrant therapeutic recombinant protein with a mixed- mode chromatography sorbent," Bioprocess International, pp. 2-6, 2009.

[8] L. A. Kennedy, W. Kopaciewicz, and F. E. Regnier, "Multimodal liquid chromatography columns for the separation of proteins in either the anion-exchange or hydrophobicinteraction mode," Journal of Chromatography A, vol. 359, pp. 73-84, 1986.

[9] N. Lončar, M. Š. Slavić, Z. Vujčić, and N. Božić, "Mixed-mode resins: taking shortcut in downstream processing of raw-starch digesting $\alpha$-amylases," Scientific Reports, vol. 5, no. 1, 2015.

[10] W. K. Chung, Y. Hou, M. Holstein, A. Freed, G. I. Makhatadze, and S. M. Cramer, "Investigation of protein binding affinity in multimodal chromatographic systems using a homologous protein library," Journal of Chromatography A, vol. 1217, no. 2, pp. 191-198, 2010.

[11] M. A. Holstein, A. A. Nikfetrat, M. Gage, A. G. Hirsh, and S. M. Cramer, "Improving selectivity in multimodal chromatography using controlled $\mathrm{pH}$ gradient elution," Journal of Chromatography A, vol. 1233, pp. 152-155, 2012.

[12] E. O'Connor, M. Aspelund, F. Bartnik et al., "Monoclonal antibody fragment removal mediated by mixed mode resins," Journal of Chromatography A, vol. 1499, pp. 65-77, 2017.

[13] M. Toueille, A. Uzel, J.-F. Depoisier, and R. Gantier, “Designing new monoclonal antibody purification processes using mixed-mode chromatography sorbents," Journal of Chromatography B, vol. 879, no. 13-14, pp. 836-843, 2011.

[14] A. Voitl, T. Müller-Späth, and M. Morbidelli, "Application of mixed mode resins for the purification of antibodies," Journal of Chromatography A, vol. 1217, no. 37, pp. 57535760, 2010.

[15] J. Vajda, E. Mueller, and E. Bahret, "Dual salt mixtures in mixed mode chromatography with an immobilized tryptophan ligand influence the removal of aggregated monoclonal antibodies," Biotechnology Journal, vol. 9, no. 4, pp. 555-565, 2014.

[16] M. Bensch, P. S. Wierling, E. von Lieres, and J. Hubbuch, "High throughput screening of chromatographic phases for rapid process development," Chemical Engineering \& Technology, vol. 28, no. 11, pp. 1274-1284, 2005. 
[17] V. B. Brochier, H. Chabre, A. Lautrette et al., "High throughput screening of mixed-mode sorbents and optimisation using pre-packed lab-scale columns for the purification of the recombinant allergen $\mathrm{rBet} \mathrm{v}$ 1a," Journal of Chromatography $B$, vol. 877, no. 24, pp. 2420-2427, 2009.

[18] W.-N. Chu, Q.-C. Wu, S.-J. Yao, and D.-Q. Lin, "Highthroughput screening and optimization of mixed-mode resins for human serum albumin separation with microtiter filter plate," Biochemical Engineering Journal, vol. 131, pp. 47-57, 2018.

[19] W.-N. Chu, Q.-C. Wu, Q.-L. Zhang, S.-J. Yao, and D.-Q. Lin, "High-throughput process development for recombinant human serum albumin separation from Pichia pastoris broth with mixed-mode chromatography," Industrial \& Engineering Chemistry Research, vol. 58, no. 8, pp. 3238-3248, 2019.

[20] W. K. Chung, A. S. Freed, M. A. Holstein, S. A. McCallum, and S. M. Cramer, "Evaluation of protein adsorption and preferred binding regions in multimodal chromatography using NMR," Proceedings of the National Academy of Sciences, vol. 107, no. 39, pp. 16811-16816, 2010.

[21] M. Zhu and G. Carta, "Protein adsorption equilibrium and kinetics in multimodal cation exchange resins," Adsorption, vol. 22, no. 2, pp. 165-179, 2016.

[22] D. Gao, S.-J. Yao, and D.-Q. Lin, "Preparation and adsorption behavior of a cellulose-based, mixed-mode adsorbent with a benzylamine ligand for expanded bed applications," Journal of Applied Polymer Science, vol. 107, no. 1, pp. 674-682, 2008.

[23] P. F. Gomes, J. M. Loureiro, and A. E. Rodrigues, “Adsorption of human serum albumin (HSA) on a mixed-mode adsorbent: equilibrium and kinetics," Adsorption, vol. 23, no. 4, pp. 491505, 2017.

[24] P. F. Gomes, J. M. Loureiro, and A. E. Rodrigues, “Adsorption equilibrium and kinetics of immunoglobulin $\mathrm{g}$ on a mixedmode adsorbent in batch and packed bed configuration," Journal of Chromatography A, vol. 1524, pp. 143-152, 2017.

[25] Q.-C. Wu, D.-Q. Lin, W. Shi, Q.-L. Zhang, and S.-J. Yao, “A mixed-mode resin with tryptamine ligand for human serum albumin separation," Journal of Chromatography A, vol. 1431, pp. 145-153, 2016.

[26] Y.-K. Chang, S.-Y. Chou, J.-L. Liu, and J.-C. Tasi, “Characterization of BSA adsorption on mixed mode adsorbent," Biochemical Engineering Journal, vol. 35, no. 1, pp. 56-65, 2007.

[27] S. Ghose, B. Hubbard, and S. M. Cramer, "Protein interactions in hydrophobic charge induction chromatography (hcic)," Biotechnology Progress, vol. 21, no. 2, pp. 498-508, 2005.

[28] D. Gao, D.-Q. Lin, and S.-J. Yao, "Measurement and correlation of protein adsorption with mixed-mode adsorbents taking into account the influences of salt concentration and $\mathrm{pH}$," Journal of Chemical \& Engineering Data, vol. 51, no. 4, pp. 1205-1211, 2006.

[29] B. K. Nfor, M. Noverraz, S. Chilamkurthi, P. D. Verhaert, L. A. van der Wielen, and M. Ottens, "High-throughput isotherm determination and thermodynamic modeling of protein adsorption on mixed mode adsorbents," Journal of Chromatography A, vol. 1217, no. 44, pp. 6829-6850, 2010.

[30] J. M. Mollerup, "Applied thermodynamics: a new frontier for biotechnology," Fluid Phase Equilibria, vol. 241, no. 1-2, pp. 205-215, 2006.

[31] J. M. Mollerup, T. B. Hansen, S. Kidal, L. Sejergaard, and A. Staby, "Development, modelling, optimisation and scale- up of chromatographic purification of a therapeutic protein," Fluid Phase Equilibria, vol. 261, no. 1-2, pp. 133-139, 2007.

[32] J. M. Mollerup, "A review of the thermodynamics of protein association to ligands, protein adsorption, and adsorption isotherms," Chemical Engineering \& Technology, vol. 31, no. 6, pp. 864-874, 2008.

[33] J. M. Mollerup, T. B. Hansen, S. Kidal, and A. Staby, "Quality by design-thermodynamic modelling of chromatographic separation of proteins," Journal of Chromatography A, vol. 1177, no. 2, pp. 200-206, 2008.

[34] A. Werner and H. Hasse, "Experimental study and modeling of the influence of mixed electrolytes on adsorption of macromolecules on a hydrophobic resin," Journal of Chromatography A, vol. 1315, pp. 135-144, 2013.

[35] E. Hackemann, A. Werner, and H. Hasse, "Influence of mixed electrolytes on the adsorption of lysozyme, PEG, and PEGylated lysozyme on a hydrophobic interaction chromatography resin," Biotechnology Progress, vol. 33, no. 4, pp. 1104-1115, 2017.

[36] E. Hackemann and H. Hasse, "Influence of mixed electrolytes and $\mathrm{pH}$ on adsorption of bovine serum albumin in hydrophobic interaction chromatography," Journal of Chromatography A, vol. 1521, pp. 73-79, 2017.

[37] E. Hackemann and H. Hasse, "Mathematical modeling of adsorption isotherms in mixed salt systems in hydrophobic interaction chromatography," Biotechnology Progress, vol. 34, no. 5, pp. 1251-1260, 2018.

[38] N. Galeotti, E. Hackemann, F. Jirasek, and H. Hasse, "Prediction of the elution profiles of proteins in mixed salt systems in hydrophobic interaction chromatography," Separation and Purification Technology, vol. 233, p. 116006, 2020.

[39] T. S. Yang and F. E. Cunningham, "Stability of egg white lysozyme in combination with other antimicrobial substances," Journal of Food Protection, vol. 56, no. 2, pp. 153156, 1993.

[40] S. Venkataramani, J. Truntzer, and D. Coleman, “Thermal stability of high concentration lysozyme across varying $\mathrm{pH}$ : a Fourier transform infrared study," Journal of Pharmacy and Bioallied Sciences, vol. 5, no. 2, pp. 148-153, 2013.

[41] D. E. Kuehner, J. Engmann, F. Fergg, M. Wernick, H. W. Blanch, and J. M. Prausnitz, "Lysozyme net charge and ion binding in concentrated aqueous electrolyte solutions," The Journal of Physical Chemistry B, vol. 103, no. 8, pp. 13681374, 1999.

[42] A. Werner, T. Blaschke, and H. Hasse, "Microcalorimetric study of the adsorption of pegylated lysozyme and peg on a mildly hydrophobic resin: influence of ammonium sulfate," Langmuir, vol. 28, no. 31, pp. 11376-11383, 2012.

[43] C. Chang and A. M. Lenhoff, "Comparison of protein adsorption isotherms and uptake rates in preparative cationexchange materials," Journal of Chromatography A, vol. 827, no. 2, pp. 281-293, 1998.

[44] M. R. Oberholzer and A. M. Lenhoff, "Protein adsorption isotherms through colloidal energetics," Langmuir, vol. 15, no. 11, pp. 3905-3914, 1999.

[45] M. E. Lienqueo, A. Mahn, J. C. Salgado, and J. A. Asenjo, "Current insights on protein behaviour in hydrophobic interaction chromatography," Journal of Chromatography B, vol. 849, no. 1-2, pp. 53-68, 2007.

[46] J. M. Angelo, A. Cvetkovic, R. Gantier, and A. M. Lenhoff, "Characterization of crosslinked cellulosic ion-exchange 
adsorbents: 2. Protein sorption and transport," Journal of Chromatography A, vol. 1438, pp. 100-112, 2016.

[47] B. D. Bowes, H. Koku, K. J. Czymmek, and A. M. Lenhoff, "Protein adsorption and transport in dextran-modified ionexchange media. i: adsorption," Journal of Chromatography A, vol. 1216, no. 45, pp. 7774-7784, 2009.

[48] T. Blaschke, J. Varon, A. Werner, and H. Hasse, "Microcalorimetric study of the adsorption of PEGylated lysozyme on a strong cation exchange resin," Journal of Chromatography A, vol. 1218, no. 29, pp. 4720-4726, 2011. 